\title{
Investigating prospective teachers' perceived levels of efficacy towards measurement and evaluation
}

\author{
Süleyman YAMAN* \\ Sevilay KARAMUSTAFAOĞLU ${ }^{* *}$
}

\begin{abstract}
The purpose of this study was to determined prospective teachers levels of perceived efficacy on measurement and evaluation. To achieve that a Likert type scale developed by researchers was applied to 464 prospective teachers in Amasya Faculty of Education. The data were analyzed using one-way ANOVA and independent t-test based on moderator variables under investigation. The responses given to the open-ended questions by the subjects were represented the qualitative aspect of the study. Results derived from the analysies show that levels of perceived efficacy of prospective teachers on measurement and evaluation wer appeared to be low. Unqualified professors teaching measurement and evaluation clasess were identified to be reason for prospective teachers' low efficacy levels. Moreover, there were no significant difference of these prospective teachers' efficacies in terms of gender and departments where as the perceived efficacy levels were significantly different based on high school types that the participants were greaduated. The difference for high school types was found to be in favor of Teacher Training High Schools. This study was completed with some practical and theoretical implications for teacher educayors, teachers and researchers who are concerned in this field.
\end{abstract}

Keywords: Measurement and evaluation, perception of perceived efficacy, prospective teachers.

*Assist. Prof. Dr., ZKU Ereğli Education Faculty, Department of Education Sciences, Zonguldak, Turkey. E-mail: syaman@karaelmas.edu.tr

**Assist. Prof. Dr., Amasya University Education Faculty, Department of Education

Sciences, Amasya, Turkey. E-mail: sevilay.karamustafaoglu@amasya.edu.tr 


\section{SUMMARY}

Purpose and Significance: Efficacy in measurement and evaluation was an important component of both content knowledge teaching and pedagogical knowledge. Measurement and evaluation is an important facet of teaching. Teachers should have an appropriate understanding of measurement and evaluation in order to be efficacious in their fields. In contrast to these expectations, studies illustrate that both teachers and prospective teachers have not been feeling themselves as efficacious about measurement and evaluation, more specifically about using alternative evaluation techniques and tools. In the study, prospective teachers' perceived levels of efficacy about measurement and evaluation were investigated considering department, gender and high school type as moderator variables for comparisons by employing both qualitative and quantitative research methodologies.

Method: Data were collected by using both a survey and interview questionnaire developed by the researchers. For the quantitative part, Likert type "Measurement and Assessment Efficacy Scale" developed by researcher was used. One structured open-ended question attached to the efficacy scale was used to collect qualitative data. The population of the study was included total 464 junior prospective teachers in Amasya Faculty of Education studying in different departments. The sample consisted of 183 elementary education, 65 science education, 65 mathematics education, 47 social science education, 42 Turkish language education, 39 pre-school education and 23 physical education majors. The scale for determining efficacy levels contained 20 items and Cronbach' Alpha reliability for the scores on the scale was .82. To compare the groups, independent t-test and one-way ANOVA were used. For qualitative analysis, content analysis technique was used to analyze ideas of participants about their perceived efficacies about measurement and evaluation.

Results: In the study, 464 out of total 779 prospective teachers in Amasya Education Faculty were reached (59.6\%). This ratio was found as appropriate to reach meaningful inferences. As a result of the study, it was found that the participants' perceived levels of efficacy about measurement and evaluation did not differ significantly for gender and department levels $(p>.05)$. In contrast, the efficacy levels of the participants were shown to be significantly different among the participating groups in terms of high school type they graduated from $(p<.05)$. This difference was in favor of teacher training high school graduates. Of the 464, 351 prospective teachers responded to the open-ended questions to state their perceptions about 
measurement and evaluation .Crucial results derived from qualitative data indicated that the most frequent reason for inefficacy of these participants was "inappropriate educational service about issue" and the second frequent reason was "lack of practice and theoretical focus in classes in which they were enrolled".

Discussion and Conclusion: The data of the study illustrated that the prospective teachers' perceived levels of efficacy about measurement and evaluation were above average, however they did not feel themselves as very efficacious about measurement and evaluation. When these prospective teachers' perceived efficacies about measurement and evaluation taken into account, it might be considered that these teacher candidates participated in this study were not ready to see themselves as efficacious for measurement and evaluation activities. Another important result of this study was that the participants attributed their inefficacy to the sources related to learning experiences provided by faculty. Furthermore, both qualitative and quantitative data showed that there was a tendency of prospective teachers to see themselves as efficacious, but this tendency was negatively affected by inappropriate learning experiences of these candidates in measurement and evaluation classes. If the result of this study was compared with the results of the other studies in the literature, it might be seen that prospective teachers did not have enough efficacy about measurement and evaluation as expected. This situation might be a setback for future professional employment of these teachers. As a limitation, the study was conducted with convenience sampling use and so focusing only students of one faculty preparing future teachers. To generate more generalizable and meaningful results this study should be replicated or extended by employing the same instruments and methodology to the students of different faculties. 


\title{
Öğretmen Adaylarının Ölçme ve Değerlendirme Alanına Yönelik Yeterlik Algı Düzeylerinin İncelenmesi
}

\author{
Süleyman YAMAN*
}

\author{
Sevilay KARAMUSTAFAOĞLU ${ }^{* *}$
}

ÖZ: Bu çalışmada öğretmen adaylarının ölçme ve değerlendirme alanına yönelik yeterlik algı düzeyleri belirlenmeye çalışılmıştır. Bu amaçla araştırmacılar tarafından geliştirilen Likert türü ölçek Amasya Eğitim Fakültesi'nde öğrenim gören 464 öğretmen adayına uygulanmıştır. Araştırmada toplanan veriler, değişkenlerin türüne göre tek faktörlü ANOVA ve bağımsız gruplar için t-testi ile analiz edilmiştir. Öğretmen adaylarının açık uçlu soruya verdikleri cevaplar ise araştırmanın nitel boyutunu meydana getirmiştir. Verilerin analizi sonunda öğretmen adaylarının ölçme-değerlendirmeyi alanına yönelik yeterlik algı düzeylerinin çok yüksek olmadığı belirlenmiştir. Ayrıca öğretmen adaylarının yeterlik alg1 düzeylerinin cinsiyet ve programlarına göre farklılık göstermediği fakat mezun olunan ortaöğretim türüne göre farkll1lk gösterdiği belirlenmiştir. $\mathrm{Bu}$ farklılığın ise öğretmen lisesi mezunlarının lehine olduğu görülmüştür. Öğretmen adayları ölçme-değerlendirmede kendilerini yeterli görememe nedenleri olarak, yeterli eğitimi alamamalarını ve derslere alan uzmanlarının girmemesini göstermişlerdir. Araştırma ilgililere gerekli önerilerle tamamlanmıştır.

Anahtar Sözcükler: Ölçme ve değerlendirme, yeterlik algısı, öğretmen adayı.

*Yrd. Doç. Dr., ZKU Ereğli Eğitim Fakültesi, Fen Bilgisi Eğitimi Anabilim Dalı, Zonguldak, Türkiye. E-mail: syaman@karaelmas.edu.tr

** Yrd. Doç. Dr., Amasya Üniversitesi Eğitim Fakültesi, Fen Bilgisi Eğitimi Anabilim Dalı, Amasya, Türkiye. E-mail: sevilay.karamustafaoglu@amasya.edu.tr 


\section{GíRiş}

Öğretmen yeterlikleri, eğitimin niteliği üzerinde oldukça önemli olan temel becerileri kapsar. $\mathrm{Bu}$ beceriler genelde üç başlık altında ele alınır, a) alan bilgisi, b) alan eğitimi bilgisi ve c) ögretmenlik meslek bilgisi. Bu becerilerin üçüne de sahip olan öğretmenlerin, öğretim programlarının hedeflerine ulaşmasında, ikisine veya yalnızca birine sahip olan öğretmenlere göre daha başarılı olması beklenir (Haycock, 1998). Ross (1992), yüksek öğretme becerilerine sahip olan öğretmenlerin öğrencilerin başarılarını artırmada daha etkili olduklarını ifade etmiştir. Öğretmen yeterlikleri olarak belirlenen bu beceriler, öğretmenlerin sınıf organizasyonu yapmalarında ve yararlı dönüt sağlamalarında da etkilidir (Dembo ve Gibson, 1985). Ayrıca bu yeterlikler, okulda verilen eğitim ve okulun etkililiği üzerinde de oldukça önemlidir (Tracz ve Gibson, 1986). Bandura'nın yeterlik teorisine göre, öğretmenlik mesleğinin başlangıcında yeterliğe verilen önem, uzun dönemli gelişim için oldukça yararlı sonuçlar verir (Akt: Hoy ve Spero, 2005). Hem alan eğitimi hem de meslek bilgisinin önemli bir bileşeni de, ölçme ve değerlendirme konusundaki yeterliliktir. İyi bir öğretmenin genel anlamda ölçme ve değerlendirmeyi bilmesinin yanında, bu konuda alanının gerektirdiği yeterliklere de sahip olması gerekmektedir (Anderson, 2008; Stronge, Tucker ve Hindman, 2004).

Milli Eğitim Bakanlığı (MEB) tarafından öğretmen yeterliklerini belirlemek amacıyla yapılan çalışmada, öğretmenlerde ölçme ve değerlendirme konusunda bulunması gereken göstergeler belirlemiştir. $\mathrm{Bu}$ göstergeler; a) ölçme değerlendirme yöntem ve tekniklerini belirleme, b) değişik ölçme tekniklerini kullanarak öğrencilerin öğrenmelerini ölçme, c) verileri analiz ederek yorumlama, öğrencinin gelişimi ve öğrenmesi hakkında geri bildirim sağlama, ç) sonuçlara göre öğrenme-öğretmen sürecini gözden geçirme, şeklinde ifade edilmiştir (MEB, 2006). Bu göstergelerde de belirtildiği gibi, ölçme ve değerlendirme eğitim sürecinin ayrılmaz bir parçası olması yanında, bu sürecin ne derece işlediğinin belirlenmesi yönünden de oldukça önemlidir (Popham, 2002). Öğretim programlarının dört temel öğesinden (hedef/kazanım, içerik, öğrenmeöğretme süreci, ölçme ve değerlendirme) biri olan ölçme ve değerlendirme boyutu, bütün eğitim sisteminin ne ölçüde işlediğinin belirlenmesinde somut çıktılar veren bir özelliktir. Bu boyut, eğitim programlarının sağlam olup olmadığını anlama, öğretimde başvurulan yöntemlerin etkililik derecesini tespit etme, öğrencileri başarılı olabilecekleri alanlara yönlendirme, öğrencilerin öğrenme güçlüklerini belirleme ve başarılarını saptamada kullanılır (Baykul, 1992; 2000). 
$\mathrm{Bu}$ yeterliklerin yanında öğretmenlerin, yenilenen öğretim programlarının temelini oluşturan yapılandırmacı yaklaşımın gerektirdiği becerilere de sahip olmaları beklenir. Yapılandırmacı yaklaşımın en önemli özelliklerinden biri olan "bilgiyi öğrencinin kendisinin yapılandırdı̆̆ı" görüşü çerçevesinde, öğretmenlerin yeni yaklaşımın bu değişimine ayak uydurmaları bir zorunluluk haline gelmiştir (Meyer-Smith ve Mitchell, 2005). Çünkü geleneksel değerlendirme yaklaşımlarının eğitsel hedefleri gerçekleştirmede yeterli olmaması nedeniyle, yeni yaklaşımların kullanılmasının gerekliliği uzun yıllardır üzerinde uzlaşılan bir konudur (Reeves ve Okey, 1996). Bu süreçte öğrencilerin okulda aldıkları eğitim ile davranışlarında meydana gelen değişikliklerin somut olarak belirlenmesi, açıklanması ve bu bilgilerden yararlanarak yürütülen eğitimin yeniden yapılandırılmasına ihtiyaç duyulur (Burke, 1994; Kaptan, 1999). Bu yapılandırmada en önemli görevlerden birini üstlenen kişiler ise öğretmenlerdir. Öğretmenlerin ölçme ve değerlendirme konusundaki yeterlikleri, eğitimin kalitesi ve niteliği ile doğrudan ilgilidir. Çünkü bu konudaki yeterlikler, doğru sonuçlara ulaşma ve sonuçları yorumlamada oldukça etkilidir. Fakat yapılan çalışmalar, ülkemizde öğretmenlerin, gelişmiş ülkelerin aksine, ölçme ve değerlendirmeyi, dönüt vermek yerine not vermek olarak gördüklerini göstermektedir (TIMSS, 2000). Ölçme ve değerlendirmenin yalnızca not verme işlemi olarak görülmesi ise, hem öğretmenleri hem de öğrencileri yanlış yönlendirebilmektedir. Gerçekte ise, öğretmenlerin görevleri arasında yer alan ölçme ve değerlendirme işlemi zor ve karmaşık bir süreçtir (Gronlund, 2002). Etkili ölçme ve değerlendirme yapabilmek için öğretmenin bu konuda kendini iyi yetiştirmesi gereklidir.

Yeni yaklaşımların üzerinde sıklıkla durduğu ve performans, portfolyo, rubrik, öz-değerlendirme, akran değerlendirme gibi çeşitli araç ve yöntemlerle güçlenen ölçme ve değerlendirme işlemlerinin olumlu sonuçlar vermesi, bu alana daha çok önem verilmesine neden olmuştur (Kutlu, 2003). $\mathrm{Bu}$ süreçte yenilenen ilköğretim ve ortaöğretim programlarında geleneksel değerlendirme yerine alternatif değerlendirmeye geçilmesi gerektiği konusuna özellikle vurgu yapılmaktadır (MEB, 2005b; 2007). Fakat yapılan çalışmalar öğretmenlerin ölçme ve değerlendirme konusunda, özellikle de alternatif değerlendirme yöntem ve araçlarını kullanmada kendilerini yeterli görmediklerini göstermektedir (Anıl ve Acar, 2008; Çakan, 2004; Gelbal ve Kellecioğlu, 2007; Yaman, 2011). Bu çalışmalarda öne çıkan nokta ise, öğretmenlerin özellikle alternatif değerlendirme yöntem ve araçlarından çok, geleneksel yöntem ve araçları kullanmayı tercih etmeleridir. Benzer sonuçlar öğretmen adayları üzerinde yapılan çalışmalarda da görülmektedir (Birgin ve Gürbüz, 2008; Usta, Dikyol ve İnce, 2010). Birgin (2007), sınıf öğretmenliği adaylarının alternatif değerlendirme yöntemlerinin uygulamalarına yönelik 
bilgi ve beceri eksikliği yaşadıklarını ifade etmiştir. Karaca (2003) tarafından yapılan çalışmada da, sınıf, fen ve sosyal bilgiler öğretmenliği adaylarının ölçme ve değerlendirme yeterliklerinin beklenen düzeyden düşük olduğu saptanmıştır. Bu bulgular, eğitim programlarında meydana gelen değişimin, öğretmen ve öğretmen adaylarına aynı ölçüde yansımadığının bir göstergesi olarak değerlendirilebilir. Cheng (2006), bu olumsuzlukların giderilmesi için öncelikli olarak eğitim işlemini yürüten kişilerin zihinlerindeki algıların değişmesi gerektiğine vurgu yapmıştır. Bu nedenle öğretmen adaylarının ölçme ve değerlendirme konusundaki yeterliklerinin tanımlanması, sunulan eğitimin niteliğinin gözden geçirilmesi açısından önem taşımaktadır. Çünkü hizmet-içi süreçte eksik veya yanlış bilgi ve becerilerin giderilmesi, hizmet-öncesi sürece göre çok daha zahmetli ve zor hale gelmektedir.

$\mathrm{Bu}$ çalışmada öğretmen adaylarının Ölçme ve Değerlendirme konusunda kendilerini ne ölçüde yeterli algıladıkları öğrenim gördükleri program, cinsiyet ve mezun olunan lise türlerine göre karşılaştırmalı olarak incelenmiştir. Bu bağlamda çalışmanın amacı, öğretmen adaylarının ölçme ve değerlendirme konusundaki yeterlik algı düzeylerinin nicel ve nitel bulgularla ortaya konulmasidır.

\section{YÖNTEM}

Araştırmanın nicel ve nitel verileri tarama yöntemiyle toplanmıştır. Nicel verilerle öğretmen adaylarının, araştırmacılar tarafından geliştirilen Likert türündeki "Ölçme ve Değerlendirme Yeterlik Alg1 Ölçeğii”ne verdikleri cevaplara göre yeterlik algı düzeyleri belirlenmiş; nitel verilerle ise, ilgili konuda kendilerini yeterli görmeyen öğretmen adaylarının, bu durumun nedenlerine ilişkin görüş ve düşünceleri tespit edilmiştir.

\section{Örneklem}

Araştırmanın örneklemini, Amasya Eğitim Fakültesi'nde öğrenim gören 3. sınıf öğrencileri arasından uygun örnekleme tekniği ile belirlenen 183 Sinıf, 65 Fen Bilgisi, 65 Matematik, 47 Sosyal Bilgiler, 42 Türkçe ve 23 Beden Eğitimi ve Spor Öğretmenliği programından olmak üzere toplam 464 ögretmen adayı oluşmuştur. Öğretmen adaylarının 242'si kız, 222'si ise erkektir. Adayların yaş ortalamasının ise 21 olduğu belirlenmiştir. Örneklemin 3. sınıf öğrencilerinden meydana gelmesinin nedeni, Ölçme ve Değerlendirme dersinin Beden Eğitimi ve Spor Öğretmenliği (2. sinıf) dışındaki diğer programlarda 3. sınıf düzeyinde yer almasıdır. 


\section{Ölçme Aracı}

Araştırmada, öğretmen adaylarının ölçme ve değerlendirmeye alanına yönelik yeterlik algı düzeylerini tespit etmek amaciyla 20 ifadeden oluşan, Likert tipi “Ölçme-Değerlendirme Yeterlik Algı Ölçeği” kullanılmıştır (EK). Araştırmacılar tarafindan geliştirilen bu ölçeğin maddelerinin hazırlanmasında, literatür taraması yapılmış (Anderson, 2008; Baykul, 2000; Enger ve Yager, 1996; Gelbal ve Kelecioğlu, 2007; Linn ve Miller, 2005) ve çıkan sonuçlara göre öğretmen adaylarının ölçme ve değerlendirme süreçlerinin hangi boyutlarına yönelik görüş bildirecekleri tespit edilmiştir. Ayrıca ölçme aracında yer alan ifadelere ilişkin üç alan eğitimi ve eğitim bilimleri uzmanının görüşlerine başvurulmuş, böylece ölçeğin kapsam geçerliği ve ifade yeterliklerine yönelik düzenlemeler yapılmıştır.

Ölçeğin geliştirilme sürecinde, 30 ifadeden oluşan ölçme arac1, örnekleme girmeyen 130 öğretmen adayına pilot olarak uygulanmıştır. Araştırmada kullanılan örneklemin yeterliliğini ölçmek için ise KaiserMeyer-Olkin (Kaiser-Meyer-Olkin Measure of Sampling Adequacy-KMO) testi ve Barlett'in küresellik derecesi (Barlett's Test of Sphericity-BTS) kullanılmıştır. Geliş̧irilen ölçme aracının KMO test sonucunun 0,77 olduğu belirlenmiştir. Bu değer ise Field (2002)'e göre örneklem yeterliğinin "iyi”" düzeyde olduğunu göstermektedir. $\mathrm{Bu}$ araştırmada elde edilen veriler için BTS testi yüksek düzeyde anlamlıdır $(B=783,57 ; p<0,01)$. Bu sonuçlara göre, bu veriler üzerine yapılan faktör analizinin güvenilir sonuçlar verdiği söylenebilir. Ölçeğin faktör yapısını belirlemek için temel bileşenler analizi uygulanmıştır (Tabachnick ve Fidell, 1996). Analiz sonunda birden çok faktöre yüklenen ve güvenirlik düzeyini düşüren 10 ifade ölçekten çıkarılmıştır. Ölçeğin son halindeki 20 ifadenin tek faktör üzerine yüklendiği belirlenmiş ve varimax rotasyonu sonunda elde edilen faktör yük değerleri aşağıdaki Tablo 1'de gösterilmiştir.

Tablo 1. Ölçek maddelerinin döndürülmüş temel bileşenler analizi yöntemine göre

\begin{tabular}{cccc}
\multicolumn{4}{c}{ faktör yük dĕ̆erleri } \\
\hline Madde No & Faktör Yük Değeri & Madde No & Faktör Yük Değeri \\
\hline Madde2 & 0,97 & Madde17 & 0,47 \\
Madde4 & 0,78 & Madde12 & 0,46 \\
Madde19 & 0,74 & Madde5 & 0,45 \\
Madde6 & 0,68 & Madde18 & 0,44 \\
Madde8 & 0,66 & Madde10 & 0,42 \\
Madde7 & 0,66 & Madde14 & 0,42 \\
Madde9 & 0,64 & Madde16 & 0,41 \\
Madde15 & 0,63 & Madde1 & 0,41 \\
Madde13 & 0,61 & Madde20 & 0,39 \\
Madde11 & 0,56 & Madde3 & 0,37
\end{tabular}


Ölçme aracındaki maddelerin faktör yük değerlerinin, 0,966 ile 0,370 arasında değiştiği tespit edilmiştir. Comrey ve Lee (1992)'ye göre varimax rotasyonu sonunda elde edilen faktör yükleri, "0,32-0,44 aras1; kötü", "0,450,54 arası; normal”, " $0,55-0,62$ arası; iyi”, " $0,63-0,70$ arası; çok iyi” ve " 0,70 ve üzeri; mükemmel" olarak kabul edilir. Tablo incelendiğinde bu ölçme arac1 için elde edilen faktör yüklerinin, 7 madde için kötü, 3 madde için normal, 3 madde için iyi, 4 madde için çok iyi, 3 madde için de mükemmel değişim gösterdiği belirlenmiştir.

Faktör analizi ile ölçme aracının yapı geçerliği, güvenirlik analizi ile ise iç tutarlılık düzeyi hesaplanmıştır. Toplam 20 ifadeden meydana gelen ölçekle toplanan verilerin Cronbach Alfa katsayısı 0,82 olarak bulunmuştur. $\mathrm{Bu}$ katsayıya göre ölçekle elde edilen verilerin güvenilirlik düzeyinin sosyal bilimler için yeterli olduğu söylenebilir (Büyüköztürk, 2007).

Ölçekte yer alan ifadelerin cevap seçenekleri, " $5=$ Kesinlikle Kat1liyorum", "4=Kat1liyorum", "3=Kararsızım", "2=Kat1lmiyorum" ve "1=Hiç Katılmıyorum" şeklindedir. Ölçeğin aralık genişliği, "dizi geniş̧liği/grup sayısı" (Tekin, 2000) formülü ile hesaplanmış ve araştırma bulgularının değerlendirilmesinde esas alınan aritmetik ortalama aralıkları; 1,00-1,80=Kesinlikle Katılmiyorum, 1,81-2,60=Kat1lmıorum, 2,613,40=Kararsızım, 3,41-4,20=Katılıorum ve 4,21-5,00=Hiç Katılıyorum şeklindedir. Ölçekteki puanlar, 1,00 ile 5,00 arasında olduğundan, puanlar 5,00'e yaklaştıkça öğretmen adaylarının ifadelere katılım düzeylerinin yüksek, 1,00'e yaklaştıkça ise düşük olduğu kabul edilmiştir. Ölçme aracında olumsuz cümle yapısı kullanılmamıştır.

Ölçme aracı, 3. sınıf öğretmen adaylarına bahar yarıyılı dersleri bittikten sonra uygulanmıştır. Bunun temel gerekçesi ise, örnekleme giren bütün programlarda öğrenim gören adayların Ölçme ve Değerlendirme kavramlarının öğretimine yönelik lisans dersini almış olmalarıdır.

\section{Verilerin Analizi}

Toplanan nicel veriler SPSS paket programına aktarılmıştır. Verilerin aritmetik ortalama ve standart sapma değerleri ile gruplar arasındaki karşılaştırmalarda bağımsız gruplar için t-testi ve tek faktörlü varyans analizi (ANOVA) kullanılmıştır. Gruplar arasında farklılık olup olmadığ $1 \% 95$ güven aralığında test edilmiştir. Nitel verilerde ise içerik analizi ile öğretmen adaylarının ölçme ve değerlendirme konusuna yönelik görüş ve düşünceleri belirlenmiştir. Cevaplarda tekrarlanan ifadeler kodlanarak kategorilere ayrılmış ve analiz edilmiştir. 


\section{BULGULAR}

$\mathrm{Bu}$ bölümde öğretmen adaylarının ölçme ve değerlendirme konusuna yönelik yeterlik algı düzeyleriyle ilgili nicel veriler farklı değişkenlere göre; açık uçlu sorunun analizi ise öğretmen adaylarının verdikleri ortak ve farklı görüşlere göre nitel bulgu olarak sunulmuştur.

\section{Nicel Verilerin Analizi}

Tablo 2'de çalışma evrenine giren öğretmen adaylarının programlarına ve cinsiyetlerine göre toplam sayıları ile örneklemde yer alan öğretmen adaylarının sayıları verilmiştir.

Tablo 2. Çalışma evreni ile örneklem oranlarina iliskin betimsel istatistik sonuçları

\begin{tabular}{|c|c|c|c|c|c|}
\hline \multirow[b]{2}{*}{ Programlar } & \multicolumn{2}{|c|}{ Çalışma Evreni (ÇE) } & \multicolumn{2}{|c|}{ Örneklem (Ö) } & \multirow{2}{*}{$\begin{array}{c}\text { ÇE/ } \\
\text { Ö } \\
\%\end{array}$} \\
\hline & $\begin{array}{c}\text { Kiz } \\
\mathbf{f}\end{array}$ & $\begin{array}{c}\text { Erkek } \\
\text { f } \\
\end{array}$ & $\begin{array}{c}\text { Kiz } \\
\mathbf{f}\end{array}$ & $\begin{array}{c}\text { Erkek } \\
\text { f }\end{array}$ & \\
\hline Beden Eğitimi ve Spor & 7 & 20 & 4 & 19 & 85,2 \\
\hline Fen Bilgisi & 44 & 90 & 34 & 31 & 48,5 \\
\hline Okul Öncesi & 38 & 4 & 36 & 3 & 92,9 \\
\hline Matematik & 53 & 48 & 28 & 37 & 64,4 \\
\hline Sınıf Öğretmenliği & 141 & 142 & 101 & 82 & 64,7 \\
\hline Sosyal Bilgiler & 27 & 61 & 17 & 30 & 53,4 \\
\hline Türkçe & 46 & 58 & 22 & 20 & 40,4 \\
\hline Toplam & 356 & 423 & 242 & 222 & 506 \\
\hline Genel Toplam & \multicolumn{2}{|c|}{779} & \multicolumn{2}{|c|}{464} & 59,0 \\
\hline
\end{tabular}

Tablo 2'ye göre Beden Eğitimi ve Spor ile Okul Öncesi programında öğrenim gören öğretmen adaylarının tamamına yakınına, Türkçe ve Fen Bilgisi programında öğrenim gören öğretmen adaylarının ise yaklaşık 1/2'sine ulaşılmıştır. Ayrıca kız öğretmen adaylarının katılım oranı (\%68) erkek öğretmen adaylarından $(\% 52,5)$ daha yüksektir. Genel toplam incelendiğinde eğitim gören 779 öğretmen adayından 464'üne ulaşıldığı belirlenmiş, bu değerin ise Amasya Eğitim Fakültesi'nde 3. sınıfta öğrenim gören toplam öğretmen adaylarının sayısının yaklaşık 3/5'i $(\% 59,6)$ olduğu tespit edilmiştir. Yani araştırmanın örneklemi, çalışma evreninin yarısından fazlasını kapsamaktadır. 
Tablo 3. Programlara göre yeterlik puanlarına ilişkin tek faktörlü ANOVA

\begin{tabular}{|c|c|c|c|c|c|c|c|}
\hline No & Programlar & $\mathbf{N}$ & $\overline{\mathbf{X}}$ & $\mathbf{S}$ & sd & $\mathbf{F}$ & $\mathbf{p}$ \\
\hline 1 & Beden Eğitimi ve Spor & 23 & 3,40 & 0,45 & $6-457$ & 1,85 & 0,09 \\
\hline 2 & Fen Bilgisi & 65 & 3,28 & 0,48 & & & \\
\hline 3 & Okul Öncesi & 39 & 3,44 & 0,39 & & & \\
\hline 4 & Matematik & 65 & 3,48 & 0,42 & & & \\
\hline 5 & Sosyal Bilgiler & 47 & 3,25 & 0,42 & & & \\
\hline 6 & Sınıf Öğretmenliği & 183 & 3,36 & 0,48 & & & \\
\hline 7 & Türkçe & 42 & 3,35 & 0,41 & & & \\
\hline \multicolumn{2}{|c|}{ Toplam } & 464 & 3,36 & 0,46 & & & \\
\hline
\end{tabular}

Tablo 3 incelendiğinde, öğretmen adaylarının eğitim gördükleri programlara göre ölçme ve değerlendirme konusundaki yeterlik alg1 puanlarının anlamlı düzeyde farklılık göstermediği tespit edilmiştir $(p>0,05)$. Aritmetik ortalama puanları incelendiğinde ölçme ve değerlendirme konusunda en yüksek yeterlik alg1 puanının Matematik Öğretmenliği $(\bar{X}=3,48)$ adaylarına ait olduğu, bunu sirasi ile Okul Öncesi $(\bar{X}=3,44)$, Beden Eğitimi ve Spor $(\bar{X}=3,40)$, Sinıf $(\bar{X}=3,36)$ ve Türkçe $(\bar{X}=3,35)$ öğretmenliği adaylarının izledikleri belirlenmiştir. Fen Bilgisi $(\bar{X}=3,28)$ ve Sosyal Bilgiler $(\bar{X}=3,25)$ öğretmenliği adaylarının ise en düşük yeterlik algı puanlarına sahip oldukları görülmüştür. Standart sapma değerlerine göre ise, yeterlik alg1 düzeyleri yönünden en fazla değişkenlik gösteren öğretmen adaylarının Matematik ve Sınıf $(S=0,48)$, en az değişkenlik gösterenin ise Okul Öncesi $(S=0,39)$ öğretmenliği adayları olduğu belirlenmiştir.

Tablo 4. Cinsiyete göre yeterlik puanlarına ilişkin bağımsız gruplar t-testi sonuçları

\begin{tabular}{lcccccc}
\hline Grup & N & $\overline{\mathbf{X}}$ & $\mathbf{S}$ & sd & t & $\mathbf{p}$ \\
\hline Kaz & 242 & 3,34 & 0,46 & 462 & $-1,29$ & 0,20 \\
Erkek & 222 & 3,39 & 0,46 & & & \\
\hline
\end{tabular}

Tablo 4'e göre kız ve erkek öğretmen adaylarının ölçme ve değerlendirme yeterlik algı puanlarının anlamlı düzeyde farklılaşmadığı belirlenmiştir $(p>, 05)$. Standart sapma değerine göre kız ve erkek öğretmen adaylarının ölçme ve değerlendirme konusundaki yeterlik algı düzeylerinin benzerlik gösterdikleri söylenebilir.

Tablo 5. Mezun olunan ortaögrretim türlerine göre yeterlik puanlarına ilişkin tek faktörlü ANOVA sonuçları

\begin{tabular}{llcccccc}
\hline No & Programlar & $\mathbf{N}$ & $\overline{\mathbf{X}}$ & $\mathbf{S}$ & $\mathbf{s d}$ & $\mathbf{F}$ & $\mathbf{p}$ \\
\hline 1 & Genel Lise & 239 & 3,33 & 0,46 & $2-461$ & 3,51 & 0,03 \\
2 & Yabanc1 Dil Ağ. Lise & 156 & 3,35 & 0,45 & & & \\
3 & Öğretmen Lisesi & 69 & 3,50 & 0,45 & & & \\
Toplam & $\mathbf{4 6 4}$ & 3,36 & 0,46 & & & \\
\hline
\end{tabular}


Tablo 5'e göre, öğretmen adaylarının mezun oldukları ortaöğretim türüne göre ölçme ve değerlendirme yeterlik algı puanlarının anlamlı düzeyde farkl1lı gösterdiği belirlenmiştir $(F(2-261)=3,51 ; \quad p<0,05)$. Farklılığın yönünü belirlemek için Scheffé testi yapılmış ve farklılığın "Öğretmen Lisesi" mezunlarıyla "Genel Lise" ve "Yabancı Dil Ağırlıklı Lise" mezunları arasında olduğu görülmüştür. Aritmetik ortalama puanlarına göre Öğretmen Lisesinden $(\bar{X}=3,50)$ mezun olan adayların ölçme ve değerlendirme konusundaki yeterlik algı düzeyleri, Genel Lise $(\bar{X}=3,33)$ ve Yabanc1 Dil Ağırlıklı Lise $(\overline{\mathrm{X}}=3,35)$ mezunlarının yeterlik alg1 düzeylerinden belirgin şekilde yüksektir. Standart sapma değerlerine göre ise, öğretmen adaylarının kendi bulundukları grup içinde yeterlik alg1 düzeylerinin benzeşiklik gösterdiği söylenebilir.

\section{Açık Uçlu Sorunun Analizi}

$\mathrm{Bu}$ kısımda görüşme formunda yer alan açık uçlu soruya verilen cevaplardan sağlanan nitel bulgular sunulmuştur. $\mathrm{Bu}$ sorunun analizi, adayların öğrenim gördükleri programlara ve verdikleri cevapların ortak ve farklı olmasına göre kategorilere ayrılmış ve Tablo 6'da sunulmuştur.

Tablo 6 incelendiğinde, öğretmen adaylarından 351 tanesi ölçme ve değerlendirme konusunda yetersiz olma nedenine ilişkin görüş belirtirken, 113 tanesi kendilerini yeterli gördüklerini ifade etmiş̧lerdir. Yetersizlik nedenleri içinde en fazla "verilen eğitimin yetersiz olması" konusunda görüş belirtilirken, "derslerin teorik olarak işlenmesi ve uygulama yapılmaması" yetersizliğin ikinci öncelikli nedeni olarak belirtilmiştir. Öğretmen adaylarının KPSS'nin içeriğinde olan bu "konunun önemini geç fark etme" ve "öğretim elemanının dersleri planlı işlememesi" de ön plana çıkan nedenler arasındadır. Fakültede "alan derslerine önem verilmesinden" ve "ilgi eksikliği hissetmekten" kaynaklanan yetersizlik ise daha az öğretmen adayı tarafından ifade edilmiştir. Sonuçlara göre, ölçme ve değerlendirme konusunda yetersiz olduğunu belirten öğretmen adaylarının, bu yetersizlik alg1 nedenlerinin büyük ölçüde kendilerinden değil de, daha çok kendilerine verilen eğitim hizmetindeki yetersizliklerden kaynaklandığını savundukları görülmektedir. Yani ögretmen adaylarının yaklaşık \%88'i yetersizlik nedeni olarak diş nedenlerin etkili olduğunu belirtirken, yaklaşı \%12'si yetersizliğin kendilerinden kaynaklandığını ifade etmişlerdir. 
Tablo 6. Öğretmen adaylarının programlarına göre ölçme ve değerlendirme konusundaki yetersizlik nedenlerine ilişkin bulgular

\begin{tabular}{ccc}
\hline \multicolumn{2}{c}{ Yetersizlik Nedenleri } \\
\hline Dişsal & İçsel \\
Nedenler & Nedenler \\
\hline
\end{tabular}

\begin{tabular}{|c|c|c|c|c|c|c|c|c|c|c|c|}
\hline Programlar & 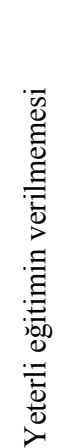 & 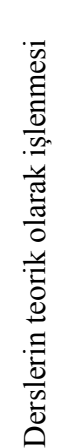 & 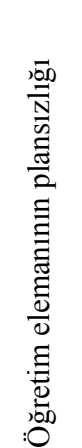 & 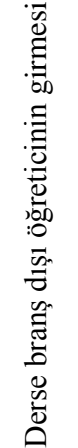 & 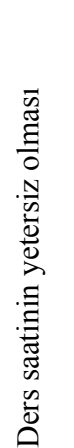 & 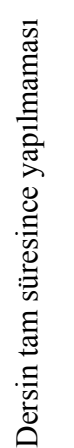 & 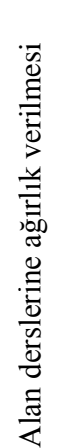 & 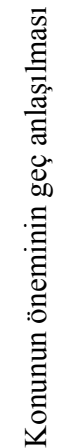 & 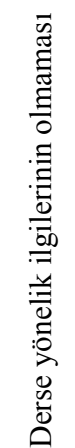 & 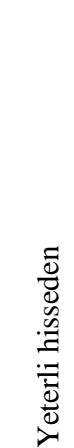 & 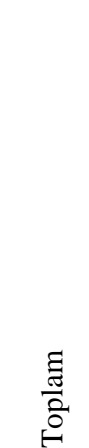 \\
\hline Beden Ĕ̆. ve Spor & 2 & & & & & & & & & 21 & 23 \\
\hline Fen Bilgisi & 20 & 13 & & 4 & 2 & & 6 & 1 & 4 & 15 & 65 \\
\hline Okul Öncesi & & & 1 & 5 & & 3 & & & & 30 & 39 \\
\hline Matematik & 20 & 15 & & & & & 2 & 1 & 2 & 25 & 65 \\
\hline Sinif & 50 & 25 & 31 & 8 & 14 & 9 & & 35 & & 11 & 183 \\
\hline Sosyal Bilgiler & 28 & 3 & & 5 & & & & & & 11 & 47 \\
\hline Türkçe & 16 & 5 & & 1 & & 3 & & & & 17 & 42 \\
\hline & & & & & & & & & & 113 & \\
\hline
\end{tabular}

\section{TARTISYMA, SONUÇ VE ÖNERILER}

Araştırmada, öğretmen adaylarının cinsiyetleri ve öğrenim gördükleri programlara göre yeterlik alg1 düzeylerinin anlamlı düzeyde farkl1l1k göstermediği belirlenmiştir. $\mathrm{Bu}$ sonuçlar, farklı cinsiyetteki ve farklı programlardan mezun olan öğretmen adaylarının hizmet-içi süreçte, benzer davranışlar sergileyecekleri şeklinde değerlendirilebilir. Adayların ölçme ve değerlendirme yeterlik algı düzeylerinin mezun oldukları ortaöğretim türüne göre ise anlamlı farklılık gösterdiği ve farklılığın Öğretmen Lisesi mezunu ögretmen adayları lehine olduğu tespit edilmiştir. Bu durumun sebebi olarak, bu liseden mezun olan öğretmen adaylarının öğretim programlarında ölçme ve değerlendirme ile ilgili dersler (MEB, 2005a) almaları gösterilebilir. Bu sonuç, programların içerik ve uygulamalarının sonraki eğitim sürecindeki etkilerini göstermesi bakımından önemlidir. Aynı zamanda sarmal programların özelliklerinden biri olan derslerin farklı yıllarda tekrar 
edilmesinin, öğrencilerin bilgileri daha kalıcı öğrenmelerinde etkili olduğu ileri sürülebilir.

Bu çalışmanın bulguları, Eğitim Fakültesinde öğrenim gören öğretmen adaylarının ölçme ve değerlendirme yeterlik algı düzeylerinin ortalamanın üzerinde olduğunu, fakat kendilerini çok yeterli görmediklerini göstermektedir. Öğretmen yeterlikleri içinde ölçme ve değerlendirmenin önemi dikkate alındığında, öğretmen adaylarının etkili ölçme ve değerlendirme yapma konusunda tam hazır olmadıkları ve kendilerini yeterli görmedikleri söylenebilir. Araştırmanın nitel bulguları incelendiğinde, öğretmen adaylarının en fazla, Fakültede aldıkları eğitimin yetersizliğine vurgu yaptıkları görülmektedir. Bu durum da, öğretmen adaylarının ölçme ve değerlendirme alanına yönelik algılanan yeterlik düzeyleri üzerinde olumsuz bir faktör olarak dikkat çekmektedir. Bazı adayların ifade ettiği, ölçme ve değerlendirme derslerine branş uzmanının girmemesi ve derslerin yalnızca teorik olarak işlenmesi de, yeterlik düzeyinin yüksek olmamasının önemli nedenleri olarak dikkat çekmektedir. $\mathrm{Bu}$ çalışmanın önemli sonuçlarından biri de, öğretmen adaylarının ilgili konudaki yetersizlik nedenlerinin çoğunun kaynağını fakültede yapılan eğitimde görmeleridir. $\mathrm{Bu}$ çalışmanın nicel ve nitel bulguları, öğretmen adaylarının kendilerini yeterli görme eğiliminde olduklarını, fakat aldıkları eğitimdeki yetersizlik ve eksikliklerin bu konudaki eğilimlerini olumsuz etkilediğini göstermektedir.

Walker (1992)'in yaptığı çalışmanın sonuçları, öğretmen adaylarının öğrenci başarısını izlemede kendilerini yeterli görmediklerini göstermektedir. Öğretmen adayları üzerinde yapılan diğer çalışmalar da benzer sonuçlar vermektedir (Birgin, 2007; Birgin ve Gürbüz, 2008; Karaca, 2003; Usta, Dikyol ve İnce, 2010). Bu çalışmanın nicel ve nitel bulguları ile diğer çalışmaların sonuçlarının gösterdiği gibi, öğretmen adaylarının ölçme ve değerlendirme konusunda beklenen düzeyde yeterlik algısına sahip olmadıkları söylenebilir. Bu durumun, öğretmenlik mesleğine atıldıklarında öğretmen adayları için önemli bir eksiklik olacağı ileri sürülebilir.

Yapılan çalışmalar ölçme ve değerlendirme konusunda yalnızca öğretmen adaylarının değil, hizmet-içi süreçte görev alan öğretmenlerin de yeterli olmadığını göstermektedir (Balcı ve Tekkaya, 1999; Çakan, 2004). $\mathrm{Bu}$ çalışmalarda, öğretmenlerin önemli bir kısmının ilgili konuda kendilerini yeterli görmedikleri tespit edilmiştir. Bir başka çalışmanın sonuçları ise öğretmenlerin öğretim becerileri konusunda kendilerini yeterli gördüklerini, fakat araştırmacılar tarafından yapılan değerlendirmede bu düzey yeterliğin düşük olduğu sonucuna vardıklarını göstermektedir (Yılmaz ve ÇoklukBökeoğlu, 2008). Öğretmen ve öğretmen adaylarının ölçme ve değerlendirme konusundaki yeterlikleri beklendiği kadar yüksek olmamasına rağmen, bu konudaki bilgi ve becerilere sahip olma tutum ve düşünceleri 
olumludur (Ogan-Bekiroğlu, 2006). Olumlu tutum, hem öğretmenlerin hem de öğretmen adaylarının bu konuda kendilerini geliştirmeye açık olduklarının bir işareti olarak kabul edilebilir. Fakat duyuşsal faktörlerin olumlu olması, eğitim sürecinde nitelikli eğitim vermek için tek başına yeterli değildir. $\mathrm{Bu}$ becerinin yanında mesleğin gerektirdiği bilişsel ve devinişsel becerilere de sahip olmak gerekmektedir.

Balc1 (2003) yaptığı araştırmada, öğretmen adayı yetiştirmede ölçme ve değerlendirme konularının öğretiminde, katılımın ve bilginin uygulanabileceği firsatların yaratılması gerektiğini vurgulamıştır. $\mathrm{Bu}$ çalışmada, öğretmen adaylarının derslerin işlenişinde uygulamaların yetersizliği konusuna yaptıkları vurgu da, yalnızca teorik olarak işlenen derslerin, öğretmen adayları tarafından yeterli görülmediğinin bir göstergesidir. Geleceğin eğitim sistemi içinde değerlendirme sürecinin farklılaşacağını belirten araştırmacılar, gerçek yaşam becerilerini temel alan ölçme-değerlendirme sürecinin en önemli olgu olacağını ileri sürmüşlerdir (Veronesi, 2000; James, Griffin ve France, 2005). Öğrencilerin ölçme ve değerlendirme sürecini algılama düzeylerinin, bilgiyi öğrenmeleri üzerinde etkili olduğu (Struyven, Dochy ve Janssens, 2005) bilgisinden hareketle, öğretmen adaylarının bu becerileri hizmet-öncesi süreçte yeterli ölçüde kazanmalarının kaçınılmaz olduğu görülmektedir. Fakat yukarıda belirtilen literatüre göre, bu becerilerdeki eksiklikler sadece öğretmen adaylarında değil öğretmenlerde de vardır. $\mathrm{Bu}$ durum, ölçme ve değerlendirme konusunun ülkemizde eğitimin her aşamasında önemli bir sorun haline geldiğinin bir göstergesidir. Bu nedenle, bu ve benzer çalışmalarda ortaya çıkan neden ve sonuçlar üzerinde yapılacak düzenlemeler, eğitim çıktılarını doğrudan etkileyecek ve eğitim kalitesinin yükselmesini sağlayacaktır.

Bu çalışmanın en önemli sınırlılığı, çalışmanın örnekleminin sadece bir fakültedeki öğretmen adaylarından oluşmasıdır. Öğretmen adaylarının ölçme ve değerlendirme alanına yönelik yeterlik algı düzeylerinin belirlenmesine yönelik yapılan bu çalışmanın sonuçlarının genellenebilmesi için farklı fakültelerde de yapılmasının yararlı olacağı söylenebilir. Ayrıca bu çalışmada kullanılan yöntem ve ölçme aracının, hizmet-içi süreçteki öğretmenlere de uygulanması, sonuçların karşılaş̧ırılmasına ve daha somut öneriler üretilmesine katkı sağlayacaktır. 


\section{KAYNAKLAR}

Anderson, L.W. (2008). Classroom assessment: Enhancing the quality of teacher decision making. New Jersey: Lawrence Erlbaum Associates.

Anıl, D., ve Acar, M. (2008). Sınıf öğretmenlerinin ölçme değerlendirme sürecinde karşılaştıkları sorunlara ilişkin görüşleri [Elementary school theachers' views on issues they experience through measurement and evaluation processes]. Yüzüncü Yll Üniversitesi Eğitim Fakültesi Dergisi, 5(2), 44-61.

Balc1, E., ve Tekkaya, C. (1999 Mart). Fen eğitiminde ölçme ve değerlendirme yaklaşımları [Measurement and evaluation approaches in science education]. Öğretmen Ĕ̈itiminde Çă̆daş Yaklaşımlar Seтроzуити, 18-20 Mart 1999, Dokuz Eylül Üniversitesi, İzmir.

Balcı, M. (2003). Fen bilgisi öğretiminde ölçme-değerlendirme üzerine bir çalışma [A study on the measurement and evaluation in the science teaching]. Milli Eğitim Dergisi, 157, 23-29.

Baykul, Y. (1992). Eğitim sisteminde değerlendirme [Assessment in educational system]. Hacettepe Üniversitesi Ĕ̈itim Fakültesi Dergisi, 7, 85-94.

Baykul, Y. (2000). Eğitimde ve psikolojide ölçme: Klasik test teorisi ve uygulamast [Measurement in education and psychology: Classical test theory and application]. Ankara: Öğrenci Seçme ve Yerleştirme Merkezi Yayınları.

Birgin, O. (2007 Eylül). Sınıf öğretmeni adaylarının ölçme ve değerlendirme konusundaki okur-yazarlık düzeylerinin incelenmesi [Primary teacher candidates' assessment and evaluation study on the literacy levels]. XVI. Ulusal Eğitim Bilimleri Kongresi, 5-7 Eylül, Gazi Osmanpaşa Üniversitesi, Tokat.

Birgin, O., ve Gürbüz, R. (2008). Sınıf öğretmeni adaylarının ölçme ve değerlendirme konusundaki bilgi düzeylerinin incelenmesi [Primary teacher canditates' level of knowledge about measurement and evaluation study]. Selçuk Ün. Sosyal Bilimler Enstitüsü Dergisi, 20, 163-180.

Burke, K. (1994). The mindful school: How to assess authentic learning. Ilinois, USA: IRI SkyLight Training and Publishing.

Büyüköztürk, Ş. (2007). Sosyal bilimler için veri analizi el kitabı [Handbook data analysis for social sciences]. Ankara: PegemA Yayıncilik.

Cheng, M.H. (2006). Junior secondary science teachers' understanding and practice of alternative assessment in Hong Kong: Implications for teacher professional development. Canadian Journal of Science, Mathematics and Technology Education, 6(3), 227-243. 
Comrey, A.L., \& Lee, H.B. (1992). A first course in factor analysis (2thed.). New Jersey, Hillsdale: Lawrence Erlbaum Associates.

Çakan, M. (2004). Öğretmenlerin ölçme-değerlendirme uygulamaları ve yeterlik düzeyleri: İlk ve ortaöğretim [Comparison of elementary and secondary school teachers in terms of their assessment practices and perceptions toward their qualification levels]. Ankara Üniversitesi Eğitim Bilimleri Fakültesi Dergisi, 37(2), 99-114.

Dembo, M.H., \& Gibson, S. (1985). Teachers' sense of efficacy: an important factor in school improvement. The Elementary School Journal, 86(2), 173-184

Enger, S.G., \& Yager, R.E. (1998). The Iowa assessment handbook. USA, Iowa: Science Education Center of the University of Iowa.

Field, A. (2002). Discovering statistics using SPSS. UK, London: Sage Pub. Ltd.

Gelbal, S., ve Kellecioğlu, H. (2007). Öğretmenlerin ölçme ve değerlendirme yöntemleri hakkındakı yeterlik algıları ve karşılaştıkları sorunlar [Teachers' proficiency perceptions of about the measurement and evaluation techniques and the problems they confront]. Hacettepe Üniversitesi Eğitim Fakültesi Dergisi, 33, 135-145.

Gronlund, N.E. (2002). Assessment of student achievement (8th ed.). Needham Heights, MA: Pearson Allyn \& Bacon.

Haycock, K. (1998). Good teaching matters: How well qualified teachers can close the gap. Thinking K-16. 3(2), 3-16.

Hoy, A.W., \& Spero, R.B. (2005). Changes in teacher efficacy during the early years of teaching: a comparison of four measures. Teaching and Teacher Education, 21, 343-356.

James, A.R., Griffin, L.L., \& France, T. (2005). Perceptions of assessment in elementary physical education: A case study. Physical Educator, 62(2), 85-95.

Kaptan, F. (1999). Fen bilgisi öğretimi [Science teaching]. İstanbul: Milli Eğitim Basımevi.

Karaca, E. (2003). Öğretmen adaylarının ölçme ve değerlendirme yeterliklerine ilişkin likert tipi bir yeterlik algısı ölçeğinin geliştirilmesi [Development of a Likert type competence perception scale towards measurement and evaluation competencies of teacher candidates]. Dumlupınar Üniversitesi Sosyal Bilimler Dergisi, 9, 179-198.

Kutlu, Ö. (2003). Cumhuriyetin 80.y1lında ölçme ve değerlendirme [Measurement and evaluation in eightieth of the Republic]. Milli Eğitim Dergisi, 160.

Linn, R. L., \& Miller, D. M. (2005). Measurement and assessment in teaching (9th ed.). Saddle River, NJ: Prentice Hall. 
MEB. (2005a). Anadolu ögrretmen lisesi haftalık ders çizelgesi [Anatolian teacher training high school weekly course schedule]. [Online]: http:// oyegm.meb.gov.tr adresinden 09 Mayss 2009 tarihinde indirilmiştir.

MEB. (2005b). İlkögretim program dosyaları [Elementary program files]. Ankara: Talim ve Terbiye Kurulu Başkanlığı. [Online]: http://ttkb.meb. gov.tr adresinden 21 Nisan 2009 tarihinde indirilmiştir.

MEB. (2006). Öğretmenlik mesleği genel yeterlikleri [General competencies of the teaching profession]. Ankara: MEB Öğretmen Yetiştirme ve Eğitimi Genel Müdürlüğü, [Online]: http//otmg.meb. gov.tr adresinden 15 Mayıs 2009 tarihinde indirilmiştir.

MEB. (2007). Ortaöğretim program dosyalart [Secondary program files]. Ankara: Talim ve Terbiye Kurulu Başkanlığı. [Online]: http://ttkb.meb. gov.tr adresinden 21 Nisan 2009 tarihinde indirilmiştir.

Meyer-Smith, J.A., \& Mitchell, I.J. (2005). Teaching about constructivism: using approaches informed by constructivism. In V. Richardson (Ed), Constructivist teacher education: Building new understandings (s. 129153), London: Taylor \& Francis, Inc.

Ogan-Bekiroğlu, F. (2006 Eylül). Fizik öğretmen adaylarının ölçme ve değerlendirmeye karşı tutumları [P hysics prospective teachers' attitudes towards assessment and evaluation]. 7. Ulusal Fen Bilimleri ve Matematik Eğitimi Kongresi, 7-9 Eylül, Gazi Üniversitesi, Ankara.

Popham, W.J. (2002). Classroom assessment: What teachers need to know? Boston: Allyn and Bacon.

Reeves, T.C. \& Okey, J.R. (1996). Alternative assessment for constructivist learning environments. In B.G. Wilson (Ed.), Constructivist learning environments: Case studies in instructional design (s. 191-202). Englewood Cliffs, NJ: Educational Technology Publications.

Ross, J.A. (1992). Teacher efficacy and the effects of coaching on student achievement. Canadian Journal of Education, 17(1), 51-65.

Stronge, J.H., Tucker, P.D., \& Hindman, J.L. (2004). Handbook for qualities of effective teachers. VA: Association of Supervision and Cur. Dev.

Struyven, K., Dochy, F., \& Janssens, S. (2005). Students' perceptions about evaluation and assessment in higher education: A review. Assessment \& Evaluation in Higher Education, 30(4), 325-341.

Tabachnick, B.G., \& Fidell, L.S. (1996). Using multivariate statistics (3th ed.). New York: Harpercollins College Publishers.

Tekin, H. (2000). Eğitimde ölçme ve değerlendirme (14. baskı) [Educational measurement and evaluation]. Ankara: Yarg1 Yayınlar1.

TIMSS. (2000). TIMSS 1999: International science reports. Boston: International Study Center Lynch School of Education, [Online]: http://timss.bc.edu adresinden 27 Mayıs 2010 tarihinde indirilmiştir 
Tracz, S.M., \& Gibson, S. (1986). Effects of efficacy on academic achievement. The Annual Meeting of the California Educational Research Association, November 13-14, Marina del Rey, CA.

Usta, S., Çığır-Dikyol, D., \& İnce, E. (2010). The alternative evaluation tools choosen by social and science teacher candidates. Procedia Social and Behavioral Sciences, 2, 3457-3462.

Veronesi, P. (2000). Testing and assessment in science education: Looking past the scoreboard. The Clearing House 74(1), 27-30.

Walker, L. (1992 November). Perceptions of preservice teacher efficacy. Annual Meeting of the Mid-South Educational Research Association, November 11-13, Knoxville, TN.

Yaman, S. (2011). Öğretmenlerin fen ve teknoloji dersinde ölçme ve değerlendirme uygulamalarına yönelik algıları [ Teachers' perceptions about their measurement and evaluation practices in science and technology course]. Illkögretim Online, 10(1), 244-256.

Yılmaz, K., ve Çokluk-Bökeoğlu, Ö. (2008). İlköğretim okulu öğretmenlerinin yeterlik inançları [Primary school teachers' belief of efficacy]. Ankara Üniversitesi Eğitim Bilimleri Fakültesi Dergisi, 41(2), 143-167. 
EK - 1

Ölçme ve Değerlendirme Yeterlik Algı Ölçeği

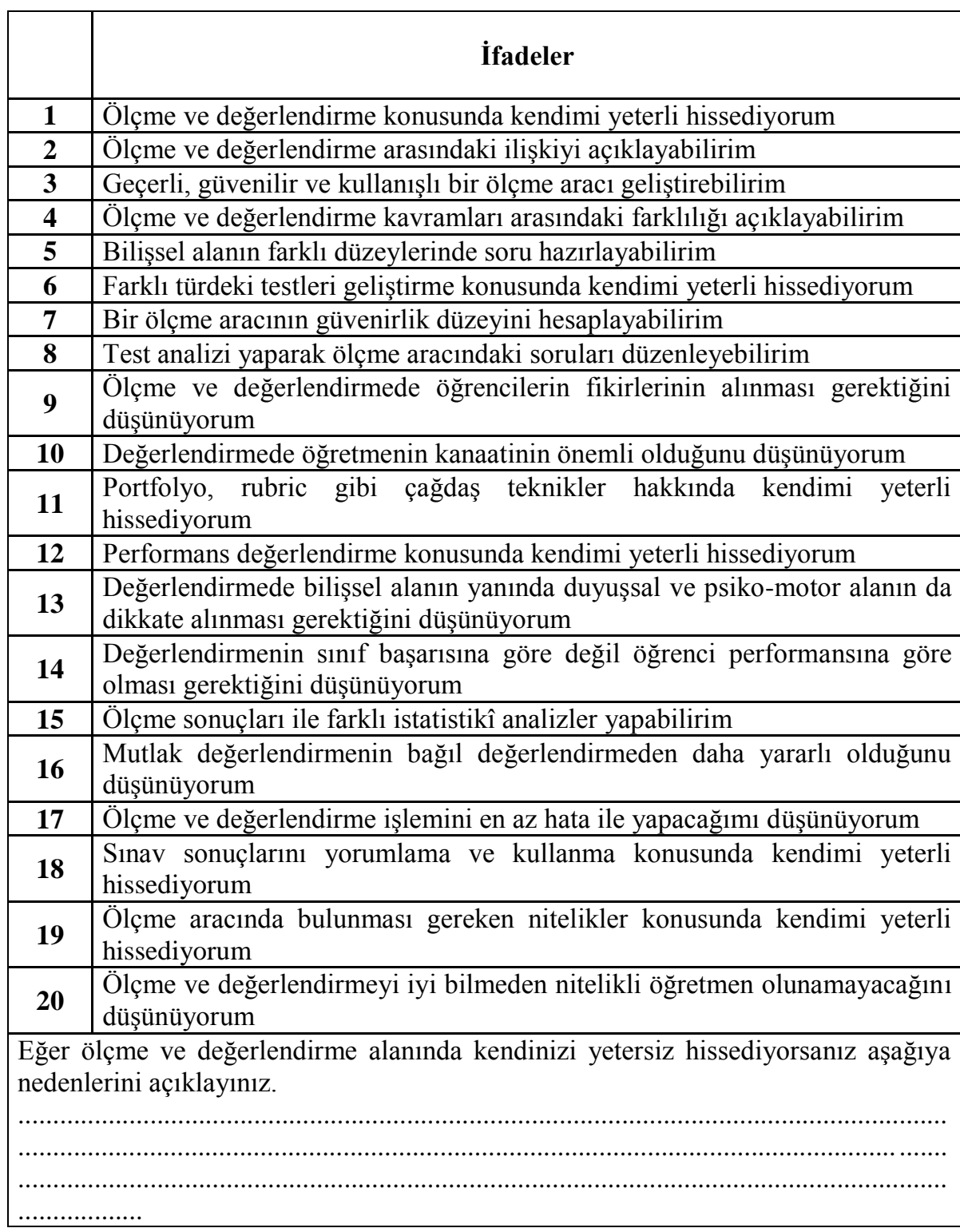

